\title{
Money's Role in the Monetary Business Cycle
}

\author{
Peter N. Ireland* \\ Boston College and NBER
}

April 2000

\begin{abstract}
A small, structural model of the monetary business cycle implies that real money balances enter into a correctly-specified, forward-looking IS curve if and only if they enter into a correctly-specified, forward-looking Phillips curve. The model also implies that empirical measures of real balances must be adjusted for shifts in money demand to accurately isolate and quantify the dynamic effects of money on output and inflation. Maximum likelihood estimates of the model's parameters take both of these considerations into account, but still suggest that money plays a minimal role in the monetary business cycle.

JEL: E31, E32, E52.
\end{abstract}

*Please address correspondence to: Peter N. Ireland, Boston College, Department of Economics, 140 Commonwealth Avenue, Chestnut Hill, MA 02467-3806. Tel: (617) 552-3687. Fax: (617) 552-2308. Email: irelandp@bc.edu. 


\section{Introduction}

For macroeconomists, recent years have been ones of heightened interest in monetary aspects of the business cycle. Analysts have devoted considerable time and effort towards developing new and improved models for monetary policy evaluation.

These newly-developed models - ranging from Rotemberg and Woodford (1997) and McCallum and Nelson's (1999) forward-looking models with microfoundations to Fuhrer and Moore's (1995) forward-looking model without microfoundations to Rudebusch and Svensson's (1999) backward-looking model without microfoundations - differ considerably in their details. One feature that is shared by all of these models, however, has to do with the minimal role that each assigns to changes in the stock of money. The Rotemberg-Woodford and Fuhrer-Moore models, for instance, make no reference whatsoever to any of the monetary aggregates. The McCallum-Nelson and Rudebusch-Svensson models include money, but only through a money demand equation that ultimately serves to determine how much money need be supplied given the levels of output, inflation, and interest rates. In none of these models do changes in the nominal or real quantities of money play a direct role in shaping the dynamic behavior of other variables. 
Do these existing models provide an accurate and complete description of money's role in the monetary business cycle? This is the question addressed here.

The paper begins, in section 2 below, by constructing a small, structural model with microfoundations that allows, but does not require, changes in the real money stock to directly affect the dynamics of output and inflation. It goes on, in section 3 , to estimate the model with quarterly time-series data from the post-1980 United States and to assess the statistical adequacy of existing specifications that assign money a minimal role.

The theoretical and empirical analyses yield several insights. First, the theoretical model contains three equations summarizing the optimizing behavior of the households and firms that populate the economy. The first of these resembles the IS curve in traditional Keynesian models, the second takes the form of a money demand relationship, and the third is a forward-looking version of the Phillips curve. Of course, real balances always enter into the money demand function. But the cross-equation restrictions imposed by the model imply that real balances enter into the IS curve if and only if they also enter into the Phillips curve specification. Thus, according to the theory, changes in the real stock of money have a direct impact on the dynamics of output if and only if they also have a direct impact on the dynamics of inflation. 
Second, the model reveals that assessing the importance of real balances in the forward-looking IS and Phillips curve specifications involves more than simply adding some measure of money to the equations and testing for the statistical significance of the associated coefficients. To isolate and quantify the effects of changes in real balances on output and inflation, the measure of money must be adjusted for shifts in money demand. Some clear intuition underlies this result. Suppose, following Taylor (1993), that actual Federal Reserve policy is best described as one that manages the short-term nominal interest rate rather than one of the monetary aggregates. Poole's (1970) analysis of a traditional Keynesian model suggests that such a policy works to insulate the economy from the effects of money demand disturbances; Ireland (forthcoming) shows that Poole's results carry over to a forward-looking, microfounded model like the one used here. Taken together, these studies imply that by managing short-term interest rates, Federal Reserve policy gives rise to changes in the money supply that simply accommodate changes in money demand, having no effect on output and inflation. Thus, a measure of real balances that is not corrected for shifts in money demand may seem unrelated to output and inflation, even when it is possible for completely exogenous movements in money to have important direct effects on both variables.

Third, and finally, the empirical analysis reveals that once the cross-equation 
restrictions and the money demand disturbances identified by the theoretical model are accounted for, changes in real balances appear to be unimportant in the model's IS and Phillips curves. Evidently, previous studies are justified in their minimal treatment of money's role in the monetary business cycle.

\section{A Small, Structural Model of the Monetary Business Cy- cle}

Here, the small, structural model developed in Ireland (1997, forthcoming) is modified to focus on the direct effects that changes in real money balances may have on the dynamics of output and inflation. This model elaborates on Rotemberg's (1982) framework, in which monopolistically competitive firms face a quadratic cost of price adjustment. Relative to the model in Ireland (1997, forthcoming), the model used here is generalized by allowing, but not requiring, real balances to appear in the IS and Phillips curve specifications. At the same time, the model is simplified, following Rotemberg and Woodford (1997), by abstracting from the process of capital accumulation.

The economy consists of a representative household, a representative finished goods-producing firm, a continuum of intermediate goods-producing firms indexed 
by $i \in[0,1]$, and a monetary authority. During each period $t=0,1,2, \ldots$, each intermediate goods-producing firm produces a distinct, perishable intermediate good. Hence, intermediate goods may also be indexed by $i \in[0,1]$, where firm $i$ produces good $i$. The model features enough symmetry, however, to allow the analysis to focus on the behavior of a representative intermediate goods-producing firm that produces the generic intermediate good $i$.

The representative household seeks to maximize the expected utility function

$$
E \sum_{t=0}^{\infty} \beta^{t} a_{t}\left\{u\left[c_{t},\left(M_{t} / P_{t}\right) / e_{t}\right]-\eta h_{t}\right\}
$$

with $1>\beta>0$ and $\eta>0$, subject to the budget constraint

$$
M_{t-1}+T_{t}+B_{t-1}+W_{t} h_{t}+D_{t} \geq P_{t} c_{t}+B_{t} / r_{t}+M_{t}
$$

which must be satisfied for all $t=0,1,2, \ldots$ In the utility function, $c_{t}$ denotes the household's consumption, $M_{t} / P_{t}$ denotes the household's real balances, and $h_{t}$ denotes the household's labor supply. The preference shocks $a_{t}$ and $e_{t}$ follow the autoregressive processes

$$
\ln \left(a_{t}\right)=\rho_{a} \ln \left(a_{t-1}\right)+\varepsilon_{a t}
$$


and

$$
\ln \left(e_{t}\right)=\left(1-\rho_{e}\right) \ln (e)+\rho_{e} \ln \left(e_{t-1}\right)+\varepsilon_{e t},
$$

where $1>\rho_{a}>0,1>\rho_{e}>0, e>0$, and the zero-mean, serially uncorrelated innovations $\varepsilon_{a t}$ and $\varepsilon_{e t}$ are normally distributed with standard deviations $\sigma_{a}$ and $\sigma_{e}$. As shown below, the shocks $a_{t}$ and $e_{t}$ translate, in equilibrium, into disturbances to the model's IS and money demand curves.

In the budget constraint, the household's sources of funds include $M_{t-1}$, nominal money carried into period $t, T_{t}$, a lump-sum nominal transfer received from the monetary authority at the beginning of period $t$, and $B_{t-1}$, the value of nominal bonds maturing during period $t$. The household's sources of funds also include labor income $W_{t} h_{t}$, where $W_{t}$ denotes the nominal wage, and nominal dividend payments $D_{t}$ received from the intermediate goods-producing firms. The household's uses of funds consist of consumption $c_{t}$ of the finished good, purchased at the nominal price $P_{t}$, newly-issued bonds of value $B_{t} / r_{t}$, where $r_{t}$ denotes the gross nominal interest rate, and the money $M_{t}$ to be carried into period $t+1$. It is convenient in what follows to let $m_{t}=M_{t} / P_{t}$ denote the household's real balances and to let $\pi_{t}=P_{t} / P_{t-1}$ denote the gross inflation rate during period $t$.

During each period $t=0,1,2, \ldots$, the representative finished goods-producing 
firm uses $y_{t}(i)$ units of each intermediate good $i \in[0,1]$, purchased at the nominal price $P_{t}(i)$, to manufacture $y_{t}$ units of the finished good according to the constantreturns-to-scale technology described by

$$
\left[\int_{0}^{1} y_{t}(i)^{(\theta-1) / \theta} d i\right]^{\theta /(\theta-1)} \geq y_{t},
$$

with $\theta>1$. The finished goods-producing firm acts to maximize its profits; the first-order conditions for its problem imply that

$$
y_{t}(i)=\left[P_{t}(i) / P_{t}\right]^{-\theta} y_{t},
$$

for all $t=0,1,2, \ldots$, which reveals that $\theta$ measures the constant price elasticity of demand for each intermediate good $i \in[0,1]$.

Competition drives the finished goods-producing firm's profits to zero in equilibrium. This zero-profit condition determines $P_{t}$ as

$$
P_{t}=\left[\int_{0}^{1} P_{t}(i)^{1-\theta} d i\right]^{1 /(1-\theta)}
$$

for all $t=0,1,2, \ldots$

During each period $t=0,1,2, \ldots$, the representative intermediate goods-producing 
firm hires $h_{t}(i)$ units of labor from the representative household to manufacture $y_{t}(i)$ units of intermediate good $i$ according to the constant-returns-to-scale technology described by

$$
z_{t} h_{t}(i) \geq y_{t}(i)
$$

The aggregate productivity shock $z_{t}$ follows the autoregressive process

$$
\ln \left(z_{t}\right)=\left(1-\rho_{z}\right) \ln (z)+\rho_{z} \ln \left(z_{t-1}\right)+\varepsilon_{z t},
$$

where $1>\rho_{z}>0, z>0$, and the zero-mean, serially uncorrelated innovation $\varepsilon_{z t}$ is normally distributed with standard deviation $\sigma_{z}$. In equilibrium, this supply-side disturbance acts as a shock to the Phillips curve.

Since the intermediate goods substitute imperfectly for one another in producing the finished good, the representative intermediate goods-producing firm sells its output in a monopolistically competitive market: the firm acts as a pricesetter, but must satisfy the representative finished goods-producing firm's demand at its chosen price. Moreover, as in Rotemberg (1982), the intermediate goodsproducing firm faces a quadratic cost of adjusting its nominal price between pe- 
riods, measured in terms of the finished good and given by

$$
\frac{\phi}{2}\left[\frac{P_{t}(i)}{\pi P_{t-1}(i)}-1\right]^{2} y_{t},
$$

with $\phi>0$, where $\pi$ measures the gross steady-state inflation rate. This cost of price adjustment makes the intermediate goods-producing firm's problem dynamic; it chooses $P_{t}(i)$ for all $t=0,1,2, \ldots$ to maximize its total market value, as described below in the appendix. At the end of each period $t=0,1,2, \ldots$, the firm distributes its profits in the form of a nominal dividend payment $D_{t}(i)$ to the representative household.

In a symmetric equilibrium, all intermediate goods-producing firms make identical decisions, so that $y_{t}(i)=y_{t}, h_{t}(i)=h_{t}, P_{t}(i)=P_{t}$, and $D_{t}(i)=D_{t}$ for all $i \in[0,1]$ and $t=0,1,2, \ldots$. The appendix shows that in such an equilibrium, the first-order conditions describing the optimizing behavior of the representative household and intermediate goods-producing firm can be approximated by

$$
\begin{aligned}
\hat{y}_{t}= & E_{t} \hat{y}_{t+1}-\omega_{1}\left(\hat{r}_{t}-E_{t} \hat{\pi}_{t+1}\right) \\
& +\omega_{2}\left[\left(\hat{m}_{t}-\hat{e}_{t}\right)-\left(E_{t} \hat{m}_{t+1}-E_{t} \hat{e}_{t+1}\right)\right]+\omega_{1}\left(\hat{a}_{t}-E_{t} \hat{a}_{t+1}\right),
\end{aligned}
$$




$$
\hat{m}_{t}=\gamma_{1} \hat{y}_{t}-\gamma_{2} \hat{r}_{t}+\gamma_{3} \hat{e}_{t},
$$

and

$$
\hat{\pi}_{t}=(\pi / r) E_{t} \hat{\pi}_{t+1}+\psi\left[\left(1 / \omega_{1}\right) \hat{y}_{t}-\left(\omega_{2} / \omega_{1}\right)\left(\hat{m}_{t}-\hat{e}_{t}\right)-\hat{z}_{t}\right] .
$$

In (4)-(6), $\hat{y}_{t}, \hat{m}_{t}, \hat{\pi}_{t}, \hat{r}_{t}, \hat{a}_{t}, \hat{e}_{t}$, and $\hat{z}_{t}$ denote the percentage (logarithmic) deviations of $y_{t}, m_{t}, \pi_{t}, r_{t}, a_{t}, e_{t}$, and $z_{t}$ from their steady-state values $y, m, \pi, r, 1$, $e$, and $z$. All of the parameters in (4)-(6) ought to be nonnegative; as shown in the appendix, each ultimately depends on the underlying parameters describing private agents' tastes and technologies. And in addition to the cross-equation restrictions that appear explicitly in (4)-(6), the constraints

$$
\gamma_{1}=\left(r-1+y r \omega_{2} / m\right)\left(\gamma_{2} / \omega_{1}\right)
$$

and

$$
\gamma_{3}=1-(r-1) \gamma_{2}
$$

must be satisfied.

Equation (4) generalizes McCallum and Nelson's (1999) forward-looking IS curve by allowing changes in real balances $\hat{m}_{t}$ to directly affect the dynamic behavior of output. The appendix shows that $\omega_{2}$ is nonzero, so that this direct 
effect is operative, when the household's utility function is nonseparable across consumption and real balances. Equation (5) takes the form of a money demand relationship with income elasticity $\gamma_{1}$ and interest semi-elasticity $\gamma_{2}$. Equation (6) is a forward-looking Phillips curve that allows changes in real balances to also have a direct impact on the dynamic behavior of inflation when $\omega_{2} \neq 0$. Thus, according to the model, real balances belong in a correctly-specified IS curve if and only if they also belong in a correctly-specified Phillips curve.

Equations (1)-(6) involve seven variables; at least one more equation is needed to close the model. Here, that equation is supplied by an interest rate rule for monetary policy:

$$
\hat{r}_{t}=\rho_{y} \hat{y}_{t}+\rho_{\pi} \hat{\pi}_{t}+\rho_{\mu} \hat{\mu}_{t}+\varepsilon_{r t}
$$

where $\rho_{y}, \rho_{\pi}$, and $\rho_{\mu}$ are parameters, where the zero-mean, serially uncorrelated policy shock $\varepsilon_{r t}$ is normally distributed with standard deviation $\sigma_{r}$, and where $\hat{\mu}_{t}$ denotes the percentage deviation of money growth $\mu_{t}=M_{t} / M_{t-1}$ from its steady state level $\mu$, so that

$$
\hat{\mu}_{t}=\hat{m}_{t}-\hat{m}_{t-1}+\hat{\pi}_{t}
$$

Like Taylor's (1993) rule, (9) calls for the monetary authority to adjust the shortterm nominal interest rate in response to deviations of output and inflation from 
their steady-state levels. Equation (9) generalizes Taylor's rule, however, by also allowing the monetary authority to respond to changes in money growth.

Ireland (forthcoming) builds on Poole's (1970) analysis by showing that in the special case where $\rho_{\mu}=0$, the monetary authority holds the interest rate fixed after a shock to money demand by accommodating the shock with a change in the money supply. Since, in this case, $\hat{m}_{t}$ and $\hat{e}_{t}$ move together, (4) and (6) imply that when $\rho_{\mu}=0$, the direct effects of changes in real balances on output and inflation can only be identified using the cross-equation restriction (7) that links $\omega_{2}$ to the

other parameters of the model. In the more general case where $\rho_{\mu} \neq 0$, however, monetary policy introduces fluctuations in $\hat{m}_{t}$ that do not simply offset movements in $\hat{e}_{t}$; the observed relationships between these independent movements in real balances and movements in output and inflation also help to identify $\omega_{2}$. Thus, in this attempt to measure the importance of money's role in the monetary business cycle, it is useful to at least allow for the possibility that Federal Reserve officials have reacted to changes in money growth, so that $\rho_{\mu} \neq 0$.

\section{Estimates and Tests}

Equations (1)-(6), (9), and (10) make up a system of eight equations in eight variables. The solution to this system, which can be found using the methods of 
Blanchard and Kahn (1980), takes the form of a state-space econometric model driven by four shocks: to the IS curve (4), to the money demand curve (5), to the Phillips curve (6), and to the policy rule (9). The model's parameters may therefore be estimated by maximum likelihood, as described by Hamilton (1994, Ch.13), using data on four variables: output, real money balances, inflation, and the short-term nominal interest rate.

Thus, in the United States data, output is measured by real GDP, real balances are measured by dividing the M2 money stock by the GDP deflator, inflation is measured by changes in the GDP deflator, and the interest rate is measured by the three-month Treasury bill rate. All data, except for the interest rate, are seasonally adjusted. The data for output and real balances are expressed in percapita terms by dividing by the civilian noninstitutional population, age 16 and over. Distinct upward trends appear in the resulting series for per-capita output and real balances, reflecting the secular growth of the United States economy; since the model requires these variables to fluctuate around constant means, a linear trend is removed from the logarithm of each prior to estimation. The data are quarterly and run from the first quarter of 1980 - also the beginning of Rotemberg and Woodford's (1997) sample - through the second quarter of 1999.

Table 1 displays maximum likelihood estimates of the model's parameters 
together with their standard errors, computed by taking the square roots of the diagonal elements of minus one times the inverted matrix of second derivatives of the maximized log likelihood function. Although all 20 parameters from (1)-(6), (9), and (10) appear in the table, only 18 of these are estimated independently, since the restrictions (7) and (8) are imposed.

Before looking specifically at the estimate of $\omega_{2}$, measuring the importance of real balances in the IS and Phillips curves, it is useful to consider some of the other estimated parameters. The estimate $\omega_{1}=0.0548$ is consistent with a rather small response of aggregate demand to changes in the real interest rate. Although the estimate $\gamma_{1}=1.4337$ implies an income elasticity of money demand that is larger than the more conventional value of one, the standard error attached to this estimate is large so that, in fact, a Wald test cannot reject the null hypothesis that $\gamma_{1}=1$. The estimate of $\gamma_{2}$ implies an interest semi-elasticity of money demand equal to 7.7532 .

While the estimate of $\rho_{y}$ is small and statistically insignificant, the larger estimates $\rho_{\pi}=0.7589$ and $\rho_{\mu}=0.8126$ indicate that Federal Reserve policy since 1980 has responded to changes in both inflation and money growth, with an increase in either variable calling forth an increase in the short-term nominal interest rate. These estimates of $\rho_{\pi}$ and $\rho_{\mu}$ sum to a value greater than one, allowing the 
interest rate rule (9) to be consistent with the existence of a unique rational expectations equilibrium, as discussed by Parkin (1978), McCallum (1981), Kerr and King (1996), and Clarida, Gali, and Gertler (2000). The finding that $\rho_{\mu}$ differs significantly from zero is particularly important since, as noted above, this implies that there are independent movements in real balances that help to identify the parameter $\omega_{2}$.

The estimates of $\ln (y), \ln (m), \ln (\pi)$, and $\ln (r)$ help the model match the average levels of detrended output, detrended real balances, inflation, and the interest rate in the data. These parameters are estimated in logs, rather than levels, to avoid scaling problems in the numerical routine that maximizes the likelihood function. The estimates of $\rho_{a}, \rho_{e}$, and $\rho_{z}$ indicate that the exogenous shocks to the IS curve (4), the money demand curve (5), and the Phillips curve (6) are quite persistent.

One estimate that deserves special mention is the estimate of $\sigma_{z}$, the standard deviation of the productivity shock. Since data on employment are not used here, this estimate comes not from the aggregate production function, as it usually does, but from the Phillips curve specification (6). In (6), the shock $\hat{z}_{t}$ is multiplied by the parameter $\psi$, which (as shown in the appendix) depends inversely on the costof-price-adjustment parameter $\phi$. Thus, as discussed more fully in Ireland (1997, 
forthcoming), productivity shocks give rise to small fluctuations in output when price adjustment costs are large. In fact, the estimate $\psi=0.0002$ shown in table 1 is consistent with a high degree of nominal rigidity, so that the model attributes less than 2 percent of the unconditional variance in output to the productivity shock. Instead, the IS shock $\hat{a}_{t}$ accounts for most of the variance in output.

Finally, the estimate $\omega_{2}=-0.0199$ is statistically insignificant; neither a Wald test nor a likelihood ratio test rejects the null hypothesis that real balances fail to enter the IS and Phillips curves. Moreover, the estimate takes the wrong sign, associating an increase in real balances with a decrease in output and an increase in inflation. These results provide formal econometric support for the minimal treatment of money in the earlier microfounded models of Rotemberg and Woodford (1997) and McCallum and Nelson (1999).

What features of the data give rise to the very small estimate of $\omega_{2}$ ? To help answer this question, table 1 also shows constrained maximum likelihood estimates of the model's parameters, obtained after imposing the restriction that $\omega_{2}$ equals the much larger value of 0.15 . With this constraint imposed, the maximized $\log$ likelihood falls from 1287.2 to 1283.1 ; a likelihood ratio test rejects constrained model at the 1 percent level. Table 2 and figure 1 then compare the empirical performance of the unconstrained model (with $\omega_{2}=-0.0199$ ) and the 
constrained model (with $\omega_{2}=0.15$ ) along the two dimensions suggested by McCallum (1999b): in terms of their abilities to match the standard deviations of the logarithms of detrended output, detrended real balances, inflation, and the shortterm nominal interest rate in the data and in terms of their abilities to match the vector autocorrelation function for the same four variables in the data.

Table 2 reveals that the unconstrained model with $\omega_{2}$ close to zero does much better than the constrained model with $\omega_{2}=0.15$ in matching the volatilities of all four variables in the data. Both models overpredict the standard deviations of output and real balances and underpredict the standard deviation of inflation, but the unconstrained model comes closer in each case. The standard deviation of the interest rate is overpredicted by the unconstrained model and underpredicted by the constrained model. Once again, however, the model with $\omega_{2}$ close to zero provides a tighter fit.

In figure 1, the vector autocorrelation function for the data is that implied by an unconstrained, fourth-order vector autoregression for the logarithms of detrended output, detrended real balances, inflation, and the short-term nominal interest rate; Fuhrer and Moore (1995) take a similar approach in characterizing the data. Unlike table 2 , figure 1 does not provide unambiguous support for the model with $\omega_{2}$ close to zero. In particular, the constrained model with $\omega_{2}=0.15$ 
does better than the unconstrained model in matching the correlations between real balances and the leads and lags of inflation and the nominal interest rate. Nevertheless, the unconstrained model provides a closer overall fit.

Thus, the unconstrained model - which assigns money a minimal role in the monetary business cycle does better in matching a variety of descriptive statistics. No one aspect of the data appears to underlie the small estimate of $\omega_{2}$ obtained here.

\section{Conclusions, Comparisons, and Caveats}

Maximum likelihood estimation of a small, structural model of the monetary business cycle suggests that real balances fail to enter the IS and Phillips curves that govern the dynamics of output and inflation. Fuhrer (1994), working with Fuhrer and Moore's (1995) forward-looking model without microfoundations, and Rude-

busch and Svensson (1999), working with their backward-looking model without microfoundations, report similar results. The microfounded model used here, however, implies that empirical measures of real balances must be adjusted for shifts in money demand in order to accurately isolate and quantify the direct effects that changes in money have on output and inflation. Thus, the results obtained here generalize those found previously: even after correcting for money demand 
shocks, money's role in the monetary business cycle appears limited.

McCallum (1999a) and Woodford (1999) calibrate forward-looking, microfounded models that are similar to the one used here. Both find values for $\omega_{2}$, the key parameter that determines whether real balances belong in the IS and Phillips curves, using cross-equation restrictions like (7) from above. McCallum chooses the setting $\omega_{2}=0.0199$, while Woodford selects the much larger setting $\omega_{2}=0.1$. Here, more formal econometric methods identify a value for $\omega_{2}$ that is even smaller than McCallum's.

Of course, these conclusions must be accompanied by several caveats. First, the data used here are from a relatively tranquil period in United States monetary history. Although, in principle, the model's parameters are structural and ought to remain invariant to changes in the monetary policy regime, it would certainly be useful to investigate whether similar estimates can be obtained with data from other periods and other countries, including those that feature wider swings in output and inflation.

In addition, while general in some respects, the small, structural model used here remains quite stylized along many dimensions. As emphasized by Nelson (1999), larger and more complicated models may serve to highlight alternative channels through which changes in money affect the economy, and future research 
must explore this possibility.

Finally, it must be noted that the results obtained here, while implying that money plays a minimal role in shaping the dynamic behavior of inflation, do not excuse the monetary authority from the important task of controlling inflation. In the model, the monetary authority must choose the steady-state rate of inflation, which is ultimately determined by the rate of nominal money growth, after adjusting for trends in output and the velocity of money, exactly as described by the quantity theory. And in the model, the monetary authority must limit the variability of inflation by vigorously adjusting its interest rate instrument in response to changes in a nominal anchor, exactly as described by Parkin (1978), McCallum (1983), Kerr and King (1996), and Clarida, Gali, and Gertler (2000).

\section{Appendix}

This appendix shows how (4)-(6) summarize the optimizing behavior of the representative household and intermediate goods-producing firm. It also shows how the parameters that enter into (4)-(6) ultimately depend on the underlying parameters describing private agents' tastes and technologies.

The representative household chooses $c_{t}, h_{t}, B_{t}$, and $M_{t}$ for all $t=0,1,2, \ldots$ to maximize its expected utility subject to its budget constraints. The first-order 
conditions for this problem can be written as

$$
\begin{gathered}
\eta=u_{1}\left(c_{t}, m_{t} / e_{t}\right) w_{t} \\
a_{t} u_{1}\left(c_{t}, m_{t} / e_{t}\right)=\beta r_{t} E_{t}\left[a_{t+1} u_{1}\left(c_{t+1}, m_{t+1} / e_{t+1}\right) / \pi_{t+1}\right], \\
r_{t} u_{2}\left(c_{t}, m_{t} / e_{t}\right)=\left(r_{t}-1\right) e_{t} u_{1}\left(c_{t}, m_{t} / e_{t}\right),
\end{gathered}
$$

and

$$
w_{t} h_{t}+d_{t}=c_{t}
$$

for all $t=0,1,2, \ldots$ In (A.1)-(A.3), $u_{1}$ and $u_{2}$ denote the derivatives of the utility function $u$ with respect to its first and second arguments, while $w_{t}=W_{t} / P_{t}$ denotes the real wage. Equation (A.4) is derived from the household's budget constraint when the market-clearing conditions $M_{t}=M_{t-1}+T_{t}$ and $B_{t}=B_{t-1}=0$ are imposed; $d_{t}=D_{t} / P_{t}$ denotes real dividends.

The representative intermediate goods-producing firm chooses $P_{t}(i)$ for all $t=$ $0,1,2, \ldots$ to maximize its total market value, given by

$$
E \sum_{t=\mathbf{0}}^{\infty} \beta^{t} a_{t} u_{1}\left(c_{t}, m_{t} / e_{t}\right)\left[D_{t}(i) / P_{t}\right]
$$


where $\beta^{t} a_{t} u_{1}\left(c_{t}, m_{t} / e_{t}\right)$ measures the marginal utility value to the representative household of an additional dollar in profits received during period $t$ and where

$$
\frac{D_{t}(i)}{P_{t}}=\left[\frac{P_{t}(i)}{P_{t}}\right]^{1-\theta} y_{t}-\left[\frac{P_{t}(i)}{P_{t}}\right]^{-\theta}\left(\frac{w_{t} y_{t}}{z_{t}}\right)-\frac{\phi}{2}\left[\frac{P_{t}(i)}{\pi P_{t-1}(i)}-1\right]^{2} y_{t}
$$

for all $t=0,1,2, \ldots$. The expression (A.5) for the firm's real dividend payment incorporates the linear production function along with the requirement that the firm supply output on demand; it also shows how the cost of price adjustment subtracts from profits. The first-order conditions for this problem are

$$
\begin{aligned}
0= & (1-\theta)\left[\frac{P_{t}(i)}{P_{t}}\right]^{-\theta}\left(\frac{y_{t}}{P_{t}}\right) \\
& +\theta\left[\frac{P_{t}(i)}{P_{t}}\right]^{-\theta-1}\left(\frac{y_{t} w_{t}}{z_{t} P_{t}}\right)-\phi\left[\frac{P_{t}(i)}{\pi P_{t-1}(i)}-1\right]\left[\frac{y_{t}}{\pi P_{t-1}(i)}\right] \\
& +\beta \phi E_{t}\left\{\left[\frac{a_{t+1} u_{1}\left(c_{t+1}, m_{t+1} / e_{t+1}\right)}{a_{t} u_{1}\left(c_{t}, m_{t} / e_{t}\right)}\right]\left[\frac{P_{t+1}(i)}{\pi P_{t}(i)}-1\right]\left[\frac{y_{t+1} P_{t+1}(i)}{\pi P_{t}(i)^{2}}\right]\right\}
\end{aligned}
$$

for all $t=0,1,2, \ldots$

In a symmetric equilibrium, where $y_{t}(i)=y_{t}, h_{t}(i)=h_{t}, P_{t}(i)=P_{t}, D_{t}(i)=$ $D_{t}$, and $y_{t}=z_{t} h_{t}$ for all $i \in[0,1]$ and $t=0,1,2, \ldots,(\mathrm{A} .4)$ and $(\mathrm{A} .5)$ can be 
combined to derive the economy's aggregate resource constraint,

$$
y_{t}=c_{t}+\frac{\phi}{2}\left(\frac{\pi_{t}}{\pi}-1\right)^{2} y_{t}
$$

while (A.1) and (A.6) can be combined to yield

$$
\begin{aligned}
\theta-1= & \theta\left[\frac{\eta}{z_{t} u_{1}\left(c_{t}, m_{t} / e_{t}\right)}\right]-\phi\left(\frac{\pi_{t}}{\pi}-1\right)\left(\frac{\pi_{t}}{\pi}\right) \\
& +\beta \phi E_{t}\left\{\left[\frac{a_{t+1} u_{1}\left(c_{t+1}, m_{t+1} / e_{t+1}\right)}{a_{t} u_{1}\left(c_{t}, m_{t} / e_{t}\right)}\right]\left(\frac{\pi_{t+1}}{\pi}-1\right)\left(\frac{y_{t+1}}{y_{t}}\right)\left(\frac{\pi_{t+1}}{\pi}\right)\right\} .
\end{aligned}
$$

Equations (A.2), (A.3), (A.7), and (A.8) imply that in the absence of shocks, the economy converges to a steady state, in which $y_{t}=y, c_{t}=c, m_{t}=m, \pi_{t}=\pi$, and $r_{t}=r$. The monetary authority must choose the steady-state inflation rate; equation (A.2) then requires that

$$
r=\pi / \beta
$$

Equation (A.7) reveals that the cost of price adjustment is zero in the steady state, so that

$$
c=y
$$


Together, (A.3) and (A.8) determine $y$ and $m$ as solutions to the two equations

$$
r u_{2}(y, m / e)=(r-1) e u_{1}(y, m / e)
$$

and

$$
(\theta-1) z u_{1}(y, m / e)=\theta \eta .
$$

Now let $\hat{y}_{t}=\ln \left(y_{t} / y\right), \hat{\pi}_{t}=\ln \left(\pi_{t} / \pi\right), \hat{m}_{t}=\ln \left(m_{t} / m\right), \hat{r}_{t}=\ln \left(r_{t} / r\right), \hat{c}_{t}=$ $\ln \left(c_{t} / c\right), \hat{\mu}_{t}=\ln \left(\mu_{t} / \mu\right), \hat{a}_{t}=\ln \left(a_{t}\right), \hat{e}_{t}=\ln \left(e_{t} / e\right)$, and $\hat{z}_{t}=\ln \left(z_{t} / z\right)$, as described in the text. A first-order Taylor approximation to (A.7) around the model's steady state implies that $\hat{c}_{t}=\hat{y}_{t}$. Hence, first-order approximations to (A.2), (A.3), and (A.8) can be written as (4)-(6) in the text, where

$$
\begin{gathered}
\omega_{1}=-\frac{u_{1}(y, m / e)}{y u_{11}(y, m / e)}, \\
\omega_{2}=-\frac{(m / e) u_{12}(y, m / e)}{y u_{11}(y, m / e)}, \\
\gamma_{2}=\frac{r}{(r-1)(m / e)}\left[\frac{u_{2}(y, m / e)}{(r-1) e u_{12}(y, m / e)-r u_{22}(y, m / e)}\right],
\end{gathered}
$$

and

$$
\psi=(\theta-1) / \phi,
$$


and where $\gamma_{1}$ and $\gamma_{3}$ are determined by $(7)$ and $(8)$ in the text.

In (A.9)-(A.11), the $u_{i j}$ 's denote the second derivatives of the utility function $u$. Thus, in particular, (A.9) shows that $\omega_{1}$ depends inversely on the household's relative risk aversion. Equation (A.10) indicates that $\omega_{2} \neq 0$, so that changes in real balances enter into the IS and Phillips curves, if and only if $u_{12} \neq 0$, so that utility is nonseparable across consumption and real balances. Finally, (A.12) reveals that the parameter $\psi$ in the Phillips curve $(6)$ is inversely related to the cost-of-price-adjustment parameter $\phi$.

\section{References}

Blanchard, Olivier Jean and Charles M. Kahn. "The Solution of Linear Difference Models Under Rational Expectations." Econometrica 48 (July 1980): 1305-1311.

Clarida, Richard, Jordi Gali, and Mark Gertler. "Monetary Policy Rules and Macroeconomic Stability: Evidence and Some Theory." Quarterly Journal of Economics 115 (February 2000): 147-180.

Fuhrer, Jeffrey C. "A Semi-Classical Model of Price-Level Adjustment: A Comment." Carnegie-Rochester Conference Series on Public Policy 41 (Decem- 
ber 1994): 285-294.

Fuhrer, Jeffrey C. and George R. Moore. "Monetary Policy Trade-offs and the Correlation between Nominal Interest Rates and Real Output." American Economic Review 85 (March 1995): 219-239.

Hamilton, James D. Time Series Analysis. Princeton: Princeton University Press, 1994.

Ireland, Peter N. "A Small, Structural, Quarterly Model for Monetary Policy Evaluation." Carnegie-Rochester Conference Series on Public Policy 47 (December 1997): 83-108.

Ireland, Peter N. "Interest Rates, Inflation, and Federal Reserve Policy Since 1980." Journal of Money, Credit, and Banking, forthcoming.

Kerr, William and Robert G. King. "Limits on Interest Rate Rules in the IS Model." Federal Reserve Bank of Richmond Economic Quarterly 82 (Spring. 1996): $47-75$.

McCallum, Bennett T. "Price Level Determinacy with an Interest Rate Policy Rule and Rational Expectations." Journal of Monetary Economics 8 (November 1981): 319-329. 
McCallum, Bennett T. "Theoretical Analysis Regarding a Zero Lower Bound on Nominal Interest Rates." Manuscript. Pittsburgh: Carnegie-Mellon University, September 1999a.

McCallum, Bennett T. "Analysis of the Monetary Transmission Mechanism: Methodological Issues." Working Paper 7395. Cambridge: National Bureau of Economic Research, October $1999 b$.

McCallum, Bennett T. and Edward Nelson. "An Optimizing IS-LM Specification for Monetary Policy and Business Cycle Analysis." Journal of Money, Credit, and Banking 31 (August 1999, Part 1): 296-316.

Nelson, Edward. "Direct Effects of Base Money on Aggregate Demand: Theory and Evidence." Manuscript. London: Bank of England, October 1999.

Parkin, Michael. "A Comparison of Alternative Techniques of Monetary Control Under Rational Expectations." Manchester School of Economic and Social Studies 46 (September 1978): 252-287.

Poole, William. "Optimal Choice of Monetary Policy Instruments in a Simple Stochastic Macro Model." Quarterly Journal of Economics 84 (May 1970): $197-216$. 
Rotemberg, Julio J. "Sticky Prices in the United States." Journal of Political Economy 90 (December 1982): 1187-1211.

Rotemberg, Julio J. and Michael Woodford. "An Optimization-Based Econometric Framework for the Evaluation of Monetary Policy." In Ben S. Bernanke and Julio J. Rotemberg, eds. NBER Macroeconomics Annual 199\%. Cambridge: MTT Press, 1997.

Rudebusch, Glenn D. and Lars E.O. Svensson. "Eurosystem Monetary Targeting: Lessons from U.S. Data." Working Paper 7179. Cambridge: National Bureau of Economic Research, June 1999.

Taylor, John B. "Discretion Versus Policy Rules in Practice." Carnegie-Rochester Conference Series on Public Policy 39 (December 1993): 195-214.

Woodford, Michael. "Price-Level Determination Under Interest-Rate Rules." Manuscript. Princeton: Princeton University, April 1999. 
Table 1. Maximum Likelihood Estimates and Standard Errors

$\begin{array}{ccccc} & \begin{array}{c}\text { Unconstrained } \\ \text { Estimate }\end{array} & \begin{array}{c}\text { Standard } \\ \text { Error }\end{array} & \begin{array}{c}\text { Constrained } \\ \text { Estimate }\end{array} & \begin{array}{c}\text { Standard } \\ \text { Error }\end{array} \\ \omega_{1} & 0.0548 & 0.0801 & 0.2554 & 0.0346 \\ \omega_{2} & -0.0199 & 0.0369 & 0.1500 & - \\ \gamma_{1} & 1.4337 & 0.4330 & 2.0620 & 0.4539 \\ \gamma_{2} & 7.7532 & 1.7544 & 6.3712 & 1.0370 \\ \gamma_{3} & 0.8553 & 0.0506 & 0.8823 & 0.0300 \\ \psi & 0.0002 & 0.0005 & 0.0011 & 0.0010 \\ \rho_{y} & 0.0288 & 0.0342 & 0.0668 & 0.0356 \\ \rho_{\pi} & 0.7589 & 0.1473 & 0.7766 & 0.1702 \\ \rho_{\mu} & 0.8126 & 0.1446 & 0.8743 & 0.1573 \\ \ln (y) & 8.8221 & 0.0140 & 8.8242 & 0.0214 \\ \ln (m) & 9.6860 & 0.0452 & 9.6915 & 0.0484 \\ \ln (\pi) & 0.0099 & 0.0029 & 0.0095 & 0.0021 \\ \ln (r) & 0.0185 & 0.0047 & 0.0183 & 0.0037 \\ \rho_{a} & 0.9426 & 0.0387 & 0.9462 & 0.0390 \\ \rho_{e} & 0.9482 & 0.0295 & 0.9439 & 0.0327 \\ \rho_{z} & 0.9308 & 0.0391 & 0.9013 & 0.0483 \\ \sigma_{a} & 0.1518 & 0.2075 & 0.0474 & 0.0151 \\ \sigma_{e} & 0.0188 & 0.0047 & 0.0171 & 0.0033 \\ \sigma_{z} & 0.7199 & 1.5277 & 0.2214 & 0.1841 \\ \sigma_{r} & 0.0062 & 0.0011 & 0.0066 & 0.0012\end{array}$


Table 2. Standard Deviations

$\begin{array}{cccc}\text { Variable } & \text { Data } & \begin{array}{c}\text { Constrained Model } \\ \text { with } \omega_{2}=0.15\end{array} \\ \ln \left(y_{t}\right) & 0.0220 & 0.0239 & 0.0357 \\ \ln \left(m_{t}\right) & 0.0547 & 0.0698 & 0.0786 \\ \ln \left(\pi_{t}\right) & 0.0054 & 0.0050 & 0.0048 \\ \ln \left(r_{t}\right) & 0.0075 & 0.0078 & 0.0071\end{array}$

Note: For both the data and the models, $\ln \left(y_{t}\right)$ and $\ln \left(m_{t}\right)$ refer to the logarithms of detrended output and detrended real balances. 

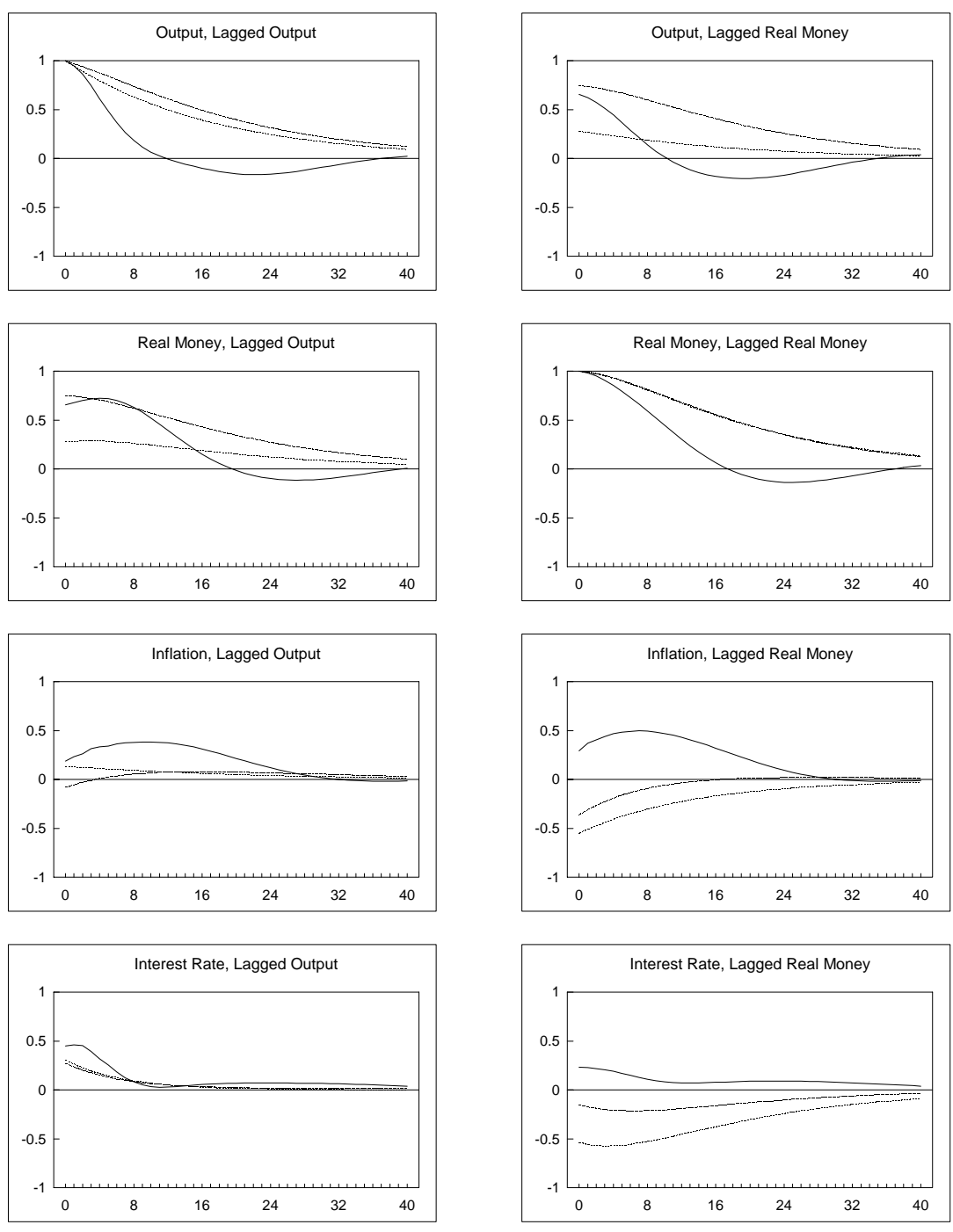
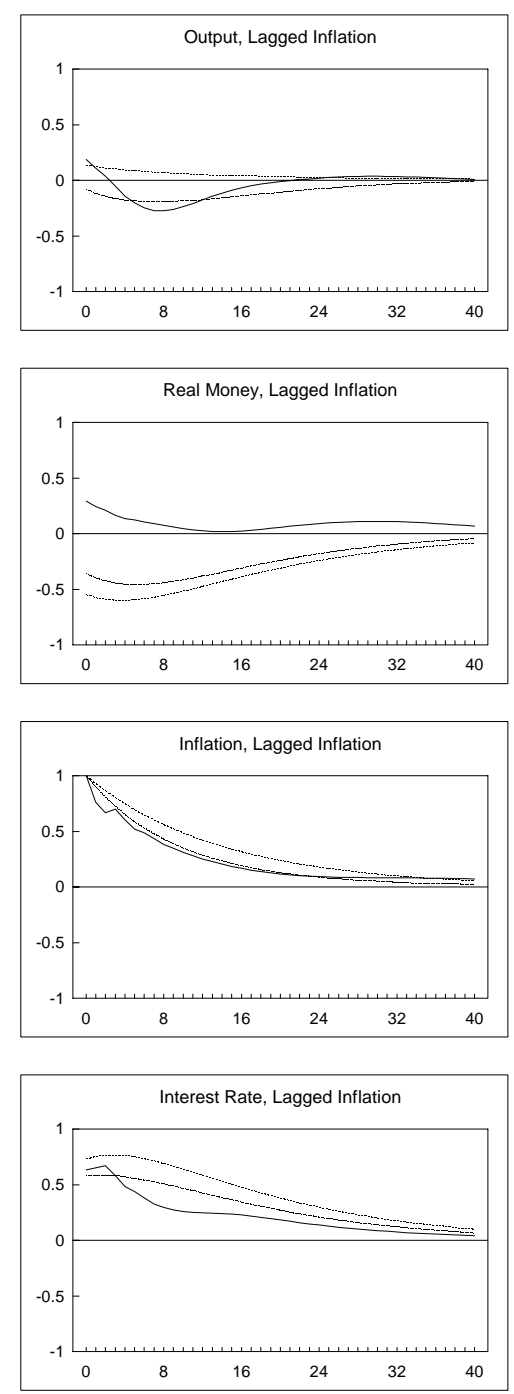
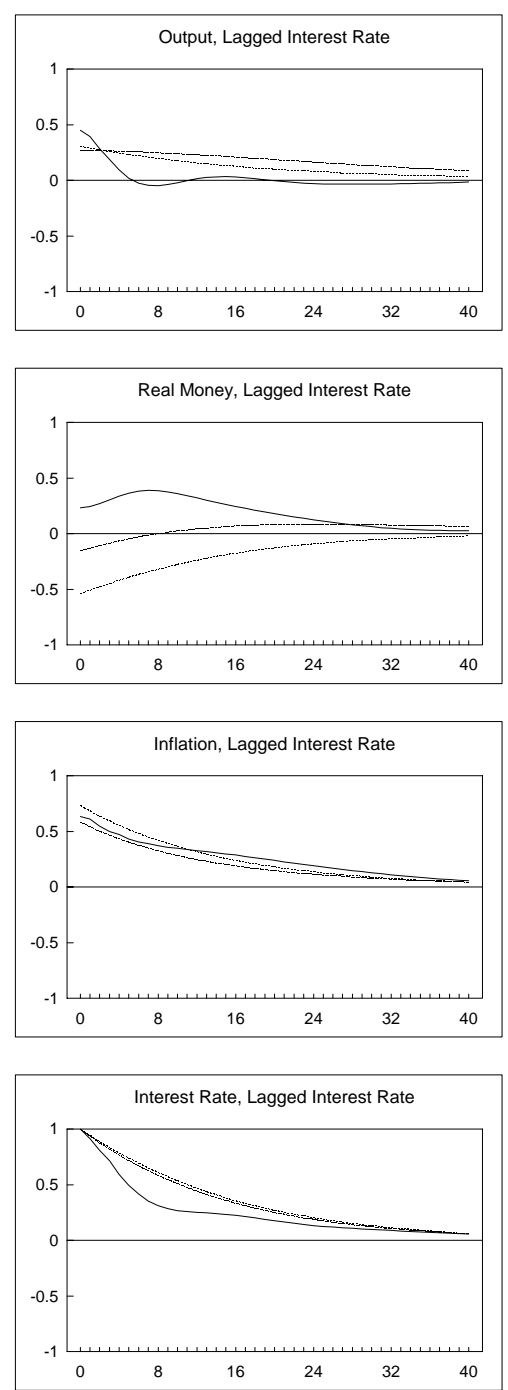

Figure 1. Vector Autocorrelation Functions

Solid line $=$ data

Dashed line $=$ unconstrained model

Dotted line $=$ constrained model 